\title{
A Review of Various Routing Protocols for Wireless Sensor Network
}

\author{
Rajinder Kaur \\ Research Scholar (ECE) \\ Maharaja Ranjit Singh \\ Punjab Technical University \\ Punjab (152004),India
}

\author{
Amit Grover \\ Assistant Professor (ECE) \\ Maharaja Ranjit Singh \\ Punjab Technical University \\ Punjab (152004), India
}

\begin{abstract}
An ad hoc network is a foundation less system . It is also called as a decentralized system in which accumulation of devices are provided with wireless communication interface. A wireless sensor network (WSN) is topographically circulated self-administering sensors. It is used to monitoring physical or ecological conditions. For example temperature, sound, weight and at the same time send the assembled data through the network to the destination. A remote sensor network (WSN) has incredible applications for example, target following and remote natural observing. This paper is about routing protocol covering their advantages and disadvantages furthermore including the correlation between these routing protocols on the basis of performance analysis.
\end{abstract}

\section{Keywords}

Ad hoc network, Wireless sensor network (WSN), Routing protocols.

\section{INTRODUCTION}

Ad hoc networks [1,11] are the accumulation of communication devices or hubs that desire to communicate with different devices without any fixed infrastructure, there is no pre-decided association of accessible connections. These individual hubs are responsible for dynamically finding different hubs through which they can be directly communicate. Extensive work has been done in the improvement of routing protocol in various types of specially appointed systems like MANETs, WMNs, WSNs, and VANETs and so on [1]. In the late years, remote sensor arrange (WSN) has turned into a tremendous research territory. The information in this system is sent, most likely by means of multiple hops, and is associated with the Internet through a Gateway [2]. Wireless sensor networks are classified into following i.e.: Flat Architecture and Hierarchical Architecture. In Flat Architecture, every hub are performing detecting undertaking and all sensor hubs are peers. However, in hierarchical architecture design, sensor hubs are composed groups where the bunch members send their information to the sink hub.

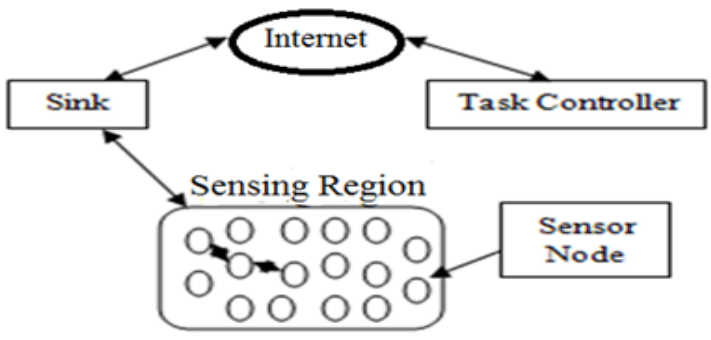

Fig. 1- Architecture of WSN
The design of WSN depends on the application considering following factors. For example, the earth, minimal effort, low vitality utilization, self-configurability, versatility, flexibility, unwavering quality, and increment the exactness of sensors, processors and particular circuits.

Hence, there is a requirement for the advancement of an enhanced technique for scalability issue in the wireless sensor network arranges that should support network scalability. Where such system should continue perform great as the system becomes bigger or as the workload increments.

In WSNs, the principle undertakings of routing protocol are course era, choice and support, and there are numerous routing protocol have been proposed for WSNs in this way. Arrangement of routing protocol in ad hoc network [3] is done in 3 ways: Reactive protocols, Proactive protocols and Hybrid protocols as appeared in figure 2 .

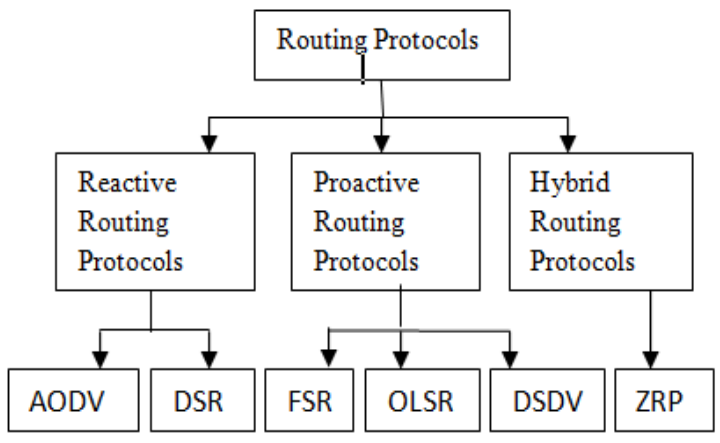

Fig. 2 - Types of Routing Protocols in Ad hoc Network

\section{REACTIVE ROUTING PROTOCOLS}

These types of protocols [9,12] are also called as on Demand Routing Protocols. A route discovery process is initiated by a source node throughout the network, only when it wants to send packets to its destination. It establishes routes "on demand" by flooding a network with a problem i.e. Route Request (RREQ) and Route Reply (RREP). Some reactive routing protocols are Ad hoc On-Demand Distance Vector (AODV), Dynamic Source Routing (DSR), etc.

\subsection{AODV Routing Protocol}

Ad hoc On-Demand Distance Vector (AODV) routing protocol $[4,12]$ is based on Distance-vector routing protocols. In Distance-vector routing, each node maintains a vector table distance vector for every node to know its neighbours and the costs to reach those paths. AODV is composed of two phases: Route Discovery and Route Maintenance. Another characteristic feature of AODV supports uni-cast, multicast and broadcast communication. AODV routing protocol use four different types of control messages that are as following: 
Route Request (RREQ) message for broadcasting messages to another nodes, Route Reply (RREP) message for message reception, Route Error (RERR) message for link failure notification and HELLO message for the links evaluation and detection. AODV routing works by using RREQ and RREP messages.

\section{Advantages of AODV}

- It reduces routing overhead.

- It has lower setup delay.

- It's bandwidth efficient so it utilizes less battery power.

\section{Disadvantages of AODV}

- AODV takes more time to build the routing tables.

- HELLO messages add a significant amount of overhead to the protocol

- $\quad$ AODV route discovery latency is high.

\subsection{Dynamic Source Routing (DSR)}

It [12] is a reactive protocol. It is based on the link-state algorithm. This type of routing protocol is specially built on a simple and efficient designed manner for its usage in multihop wireless ad-hoc networks of mobile nodes. It uses the technique of source routing rather than relying on the routing table. Dynamic source routing (DSR) is based on two mechanisms:

1. Route Discovery process.

2. Route Maintenance process.

Route Discovery process is based upon two messages i.e. Route Request (RREQ) message and Route Reply (RREP) message. In Route Maintenance process, if there is any broken line path on the source node then this node will tell the network to use Route Error (RERR) message. Then a new route discovery will be processed to find new route if it is still needed.

\section{Advantages of DSR}

- A route is established only when it is required as it is a reactive protocol.

- Route caching reduces route discovery overhead.

Disadvantages of DSR

- Route maintenance process does not restrictedly repair a broken link.

- Connection setup delay is higher in these types of protocols.

\section{PROACTIVE ROUTING PROTOCOLS}

Proactive routing protocols [9] are also termed as table-driven routing protocols are used to maintain all the route information in its routing table. In this routing protocol, every node broadcasts its routing table to all its neighbouring nodes. If there is any change in the network topology, then all the nodes in the network will propagate the route updates to maintain stable network view. Examples of these routing protocols are Optimised Link State Routing (OLSR), Fisheye State Routing (FSR), etc.

\subsection{Fisheye State Routing (FSH)}

This protocol uses a table-driven routing mechanism. It is implied as a hierarchical routing protocol. The Fisheye State
Routing (FSR) protocol $[5,12]$ uses the fisheye technique to reduce the routing overhead. In this technique, the eye of the fish can take pixel information with greater accuracy near its eye's focal point. The accuracy of the pixel decreases with the increase in distance from the focal point. In routing, this fisheye approach has the ability to translate and maintaining accurate information about near nodes and not so accurate information about far-away nodes.

Advantages of FSR

- It is suitable for large and highly mobile environments.

- It reduces routing overhead.

Disadvantages of FSR

- The performance of the network will degrade when the zone length of the FSR increases.

- Small ad-hoc networks will provide poor protocol performance.

\subsection{Optimised Link-Sate Routing (OLSR) Routing Protocol}

An OLSR $[6,7,12]$ routing protocol is an optimised routing protocol for MANETs and it can also be used on wireless adhoc network. It is a proactive routing protocol which is used only when a route is feasible directly when needed. OLSR protocol is used to reduce these flooding problems by using only MPR nodes this can be used to send information in the network. OLSR is also used to avoid unnecessary transmission of link-state packets i.e. once a packet is send to a node that node will not going to receive another copy of the same packet during its transmission. OLSR routing protocol has four kinds of messages that are as follows: HELLO messages, Topology Control (TC) messages, Mulitple Interface Declaration (MID) and Host and Network Announcement (HNA).

\section{Advantages of OLSR}

- It is well suited for an application which does not allow the long delays in the transmission of the data packets.

- Its implementation is more user friendly.

Disadvantages of OLSR

- It has wider delay distribution.

- OLSR routing protocol need more time for rediscovering a broken links.

\subsection{Destination-Sequence Distance-Vector Routing (DSDV) Routing Protocol}

Destination-Sequenced Distance-Vector Routing (DSDV) $[8,12]$ is a Proactive routing protocol. It is the hop-by-hop distance vector routing protocol demanding each node periodically maintain a routing table in which all possible destinations and the of hops in the network are recorded. Furthermore, routing table data is exchanged within the neighbor nodes and routing data is updated with new data by every node. In DSDV routing protocol a maximum size of buffering is available in memory to collect those data packets until the routing information could not received.

\section{Advantages of DSDV}

- It guarantees loop free paths.

- Count to infinity problem is reduced in DSDV. 


\section{Disadvantages of DSDV}

- DSDV doesn't support Multi path Routing.

- It is difficult to determine a time delay for advertisement of the routes.

\section{HYBRID ROUTING PROTOCOLS}

A hybrid routing protocol [10] has a consolidation features of both the routing protocols i.e. reactive and proactive routing protocols. Examples of hybrid routing protocols are as follows: ZRP (Zone Routing Protocol), TORA (Temporally Ordered Routing Algorithm), etc. This type of routing is basically used to define the best destination routes in the network along with the changes or modifications in the network topology.

\subsection{Zone Routing Protocol (ZRP)}

A Zone Routing Protocol (ZRP) is a wireless networking hybrid routing protocol having features of both reactive and pro active protocol. Each node is maintaining its zone radius and overlapping of neighboring zones occur. It is taking the advantage of reactive routing protocol for communication between node's local neighborhoods. A Zone Routing Protocol (ZRP) routing can be classified into two parts that are as follows:

\section{COMPARISON BETWEEN REACTIVE, PROACTIVE AND HYBRID ROUTING PROTOCOLS}

1. Intrazone Routing Protocol (IARP).

2. Interzone Routing Protocol (IERP).

In an Intrazone Routing Protocol (IARP), a proactive routing protocol is used to maintain the zone routing protocol inside the routing zone. Where on the other hand an Interzone Routing Protocol (IERP) uses a reactive routing protocol within its routing zone and it can also be used to discover routes to the destination reactively.

\section{Advantages of ZRP}

- Compared to reactive routing it helps to reduce the wastage of bandwidth and control overhead as well.

- Eliminate the delays for routing within a routing zone due to route-discovery process used in the reactive routing protocol.

\section{Disadvantages of ZRP}

- In zone routing protocol, a main problem occurs due to the large overlapping of routing zones.

- It requires more memory as each node in the network is having a high level topology information which may require greater memory requirements.

Table 1: Comparison of Reactive, Proactive and Hybrid routing protocol

\begin{tabular}{|c|c|c|c|}
\hline Parameters & Reactive Routing Protocol & Proactive Routing Protocol & Hybrid Routing Protocol \\
\hline Description & $\begin{array}{l}\text { On-demand routing protocol } \\
\text { which creates routes only when a } \\
\text { node requires or demand for a } \\
\text { route to a destination }\end{array}$ & $\begin{array}{l}\text { Table-driven routing protocol } \\
\text { in which all the information } \\
\text { of routes are maintained in } \\
\text { the routing table }\end{array}$ & $\begin{array}{l}\text { Combination of both reactive and } \\
\text { proactive routing protocols }\end{array}$ \\
\hline Routing philosophy & Flat & Flat & Hierarchical \\
\hline Overhead & Low & High & Reduces overhead \\
\hline Memory requirements & Low & High & Very high \\
\hline Delay & High & Low & Low \\
\hline Advantages & $\begin{array}{l}\text { Lower routing overhead, no } \\
\text { unnecessary control messages are } \\
\text { required }\end{array}$ & Lower route setup latency & $\begin{array}{l}\text { No route setup latency for short } \\
\text { distance connection, reduces control } \\
\text { overhead, minimizing delays }\end{array}$ \\
\hline Disadvantages & $\begin{array}{l}\text { High latency for finding routes, } \\
\text { route discovery packet flooding }\end{array}$ & $\begin{array}{l}\text { The cost of maintaining all } \\
\text { topology information is very } \\
\text { high, high routing overheads }\end{array}$ & $\begin{array}{l}\text { Large overlapping of routing zones, } \\
\text { large memory requirements }\end{array}$ \\
\hline
\end{tabular}

Table 2: Comparison between various routing protocols on the basics of some parameter

\begin{tabular}{|c|c|c|c|c|c|c|}
\hline Parameters & AODV & DSR & $\begin{array}{l}\text { FSR } \\
\end{array}$ & OLSR & DSDV & $\overline{\mathrm{ZRP}}$ \\
\hline $\begin{array}{l}\text { Routing } \\
\text { philosophy }\end{array}$ & On-demand & On-demand & Proactive & Proactive & Proactive & $\begin{array}{l}\text { Hybrid i.e. } \\
\text { on-demand } \\
\text { proactive } \\
\text { nature }\end{array}$ \\
\hline Routing Overhead & $\begin{array}{l}\text { Higher as } \\
\text { compared to } \\
\text { DSDV }\end{array}$ & $\begin{array}{l}\text { High } \\
\text { overhead for } \\
\text { long paths or } \\
\text { large address }\end{array}$ & $\begin{array}{lr}\text { High routing } \\
\text { overhead } & \text { with } \\
\text { respect } & \text { to } \\
\text { scalability } & \end{array}$ & Higher & Low & Low \\
\hline Control Overhead & Low & Low & $\begin{array}{l}\text { It helps in } \\
\text { reducing the } \\
\text { control message } \\
\text { overhead }\end{array}$ & $\begin{array}{l}\text { It minimizes the } \\
\text { overhead from } \\
\text { flooding of control } \\
\text { traffic }\end{array}$ & $\begin{array}{l}\text { Performance } \\
\text { varies within } \\
\text { AODV and DSR } \\
\text { routing protocols }\end{array}$ & $\begin{array}{lr}\text { Reduced } & \text { control } \\
\text { overhead for } & \text { for } \\
\text { longer routes } & \end{array}$ \\
\hline
\end{tabular}




\begin{tabular}{|c|c|c|c|c|c|c|}
\hline Loop free & $\begin{array}{l}\text { Supports } \\
\text { loop } \\
\text { freedom }\end{array}$ & Yes & Yes & Yes & Yes & Yes \\
\hline End-to-end delay & $\begin{array}{l}\text { Performance } \\
\text { decreases }\end{array}$ & $\begin{array}{l}\text { Better than } \\
\text { DSDV }\end{array}$ & Higher delay & $\begin{array}{ll}\text { Wider } & \text { delay } \\
\text { distribution } & \end{array}$ & $\begin{array}{l}\text { Higher end-to-end } \\
\text { delay }\end{array}$ & $\begin{array}{l}\text { Eliminating } \\
\text { delays for routing }\end{array}$ \\
\hline Qos Support & No & No & Yes & Yes & $\begin{array}{lr}\text { It does } & \text { not } \\
\text { support } & \text { Qos } \\
\text { services } & \end{array}$ & Yes \\
\hline $\begin{array}{l}\text { Route maintained } \\
\text { in }\end{array}$ & Route table & Route cache & Routing table & Routing table & Routing table & Routing zones \\
\hline Hello Message & Yes & Yes & No & Yes & No & Yes \\
\hline Protocol type & $\begin{array}{l}\text { Distance- } \\
\text { vector }\end{array}$ & Link-state & Link-state & Link-state & Distance-vector & $\begin{array}{l}\text { Hierarchical } \\
\text { routing }\end{array}$ \\
\hline Multipath routing & No & Yes & Yes & No & $\begin{array}{l}\text { It does not } \\
\text { support multipath } \\
\text { routing }\end{array}$ & Yes \\
\hline Scalability & Low & Low & Limited & Good & Low & Good \\
\hline Mobility & Low & Low & Low & Limited & Good & Good \\
\hline $\begin{array}{l}\text { Periodic } \\
\text { broadcast }\end{array}$ & Yes & No & Yes & Yes & Yes & Yes \\
\hline
\end{tabular}

\section{CONCLUSION AND REMARKS}

We have provided descriptions of several routing scheme proposed for mobile ad hoc networks or wireless sensor network as well. Also provided a classification of these schemes according to the routing strategy i.e. table-driven, ondemand and combination of both reactive and proactive routing protocols called as hybrid routing protocols. The advantages and disadvantages of the protocols based on their routing processes. In the last, comparison of these protocols has been considered on the basis of various parameters. As there is need for the development of an improved method for scalability issue in wireless sensor networks. Network should continue to perform well as the networks grows larger or as the work load increases.

\section{REFERENCES}

[1] Sarkar S, Basavaraju T.G. and Puttamadappa C., "Ad Hoc Mobile Wireless networks: Principles, protocols and applications", Auerbach Publications, 2008.

[2] Sohraby K, Minoli D, Znati T, "Wireless Sensor Networks: Technology, protocols and Applications", John Wiley \& sons, New York, USA, 2007.

[3] Palaniammal M, \& Lalli M, "ComparativeStudy of Routing Protocols for Manets" International Journal of Computer Science and Mobile Applications, Vol.2, Issue 2, pp. 118-127, 2014.

[4] Patil, V. P. "Reactive and proactive routing protocol performance evaluation for qualitative and quantitative analysis in mobile ad hoc network."International Journal of Scientific and Research Publications 2, Vol No. 9, pp. $1-8,2012$.

[5] Kilinkaridis, T., "Routing Protocols for Wireless Ad Hoc Networks."

[6] Jacquet, Philippe, Paul Mühlethaler, Thomas Clausen, Anis Laouiti, Amir Qayyum, and Laurent Viennot.
"Optimized link state routing protocol for ad hoc networks." In Multi Topic Conference, 2001. IEEE INMIC 2001. Technology for the 21st Century. Proceedings. IEEE International, pp. 62-68. IEEE, 2001.

[7] Clausen T, Jacquet P, RFC 3626-“Optimized Link State Routing Protocol (OLSR)”, Oct 2003.

[8] Rai, Vijendra, and Jaishree Jain. "Study and Comparison Performance of On-demand AODV and DSR, along with the traditional proactive DSDV Routing Protocols for MANET." National Conference on Emerging Trends in Advanced Computer \& Informatics, Volume 2, Issue 6, 2012.

[9] Basu Dev Shivahare, Charu Wahi, Shalini Shivhare. "Proactive And Reactive Routing Protocols In Mobile Adhoc Network Using Routing Protocol" ISSN 22502459, Volume 2, Issue 3, March 2012.

[10] Dhote, C. A., M. A. Pund, R. S. Mangrulkar, and Mr Makarand R. Shahade. "Hybrid routing protocol with broadcast reply for mobile Ad hoc network." International Journal of Computer Applications 1, vol no. $10,2010$.

[11] C. Siva Ram Murthy and B.S. Manoj. Ad Hoc WirelessNetworks Architectures and Protocol, volume SBN:81297- 0945-7. Pearson Education, edition,2005.

[12] Santa Barbara Elizabeth M. Royer and Chai Keong Toh. "A Review of Current Routing Protocols for Adhoc Mobile Wireless Networks." IEEE Personal Communications, pages 46-55, April 1999. 